\title{
Value of the Oxygen Pulse Curve for the Diagnosis of Coronary Artery Disease
}

\author{
A. DE LORENZO ${ }^{1,2}$, C. L. DA SILVA ${ }^{1}$, F. C. CASTRO SOUZA ${ }^{2}$, R. DE SOUZA LEÃO \\ LIMA $^{1}$
}

${ }^{1}$ Universidade Federal do Rio de Janeiro, Rio de Janeiro, Brazil, ${ }^{2}$ Instituto Nacional de Cardiologia, Rio de Janeiro, Brazil

Received October 26, 2017

Accepted March 16, 2018

On-line July 25, 2018

\section{Summary}

This study investigated the value of oxygen $\left(\mathrm{O}_{2}\right)$ pulse curves obtained during cardiopulmonary exercise testing (CPET) for the diagnosis of coronary artery disease (CAD). Forty patients with known coronary anatomy (35.0\% normal, $27.0 \%$ single-vessel and $38.0 \%$ multivessel CAD) underwent CPET with radiotracer injection at peak exercise, followed by myocardial scintigraphy. $\mathrm{O}_{2}$ pulse curves were classified as: A-normal, B-probably normal (normal slope with low peak value); C-probably abnormal (flat, with low peak value); or D- definitely abnormal (descending slope). Sensitivity, specificity, positive and negative predictive values of the $\mathrm{O}_{2}$ pulse curve pattern ( $A$ or $B$ vs. $C$ or $D$ ) for the diagnosis of CAD were, respectively, $38.5 \%, 81.3 \%, 76.9 \%$, and $44.8 \%$. The concordance rate between the abnormal $\mathrm{O}_{2}$ pulse curve pattern and ischemia in myocardial scintigraphy was $38.1 \%$. Age and the extent of scintigraphic perfusion defect, but not the abnormal $\mathrm{O}_{2}$ pulse curve patterns ( $\mathrm{B}$ or $\mathrm{C}$ or both combined) were independently associated with CAD. In conclusion, the $\mathrm{O}_{2}$ pulse curve pattern has low diagnostic performance for the diagnosis of obstructive $C A D$, and the abnormal curve pattern was not associated with myocardial ischemia defined by scintigraphy.

\section{Key words}

Cardiopulmonary exercise testing - Oxygen pulse - Myocardial perfusion scintigraphy - Myocardial ischemia - Coronary artery disease $\bullet$ Diagnosis

\section{Corresponding author}

A. De Lorenzo, Universidade Federal do Rio de Janeiro, Av. Brigadeiro Trompowsky $\mathrm{s} / \mathrm{n}$, Rio de Janeiro, Brazil. E-mail: andlorenzo@hotmail.com

\section{Introduction}

Cardiopulmonary exercise testing (CPET)exercise testing with ventilatory gas exchange measurements- provides a wide array of clinically useful information. While frequently employed in the heart failure scenario to assess the degree of cardiac dysfunction and prognosis, CPET has a number of other indications, from the evaluation of athletic performance in healthy individuals to testing for the presence of coronary artery disease (CAD) (Myers and Gullestad, 1998, Balady et al. 2010, Guazzi et al. 2012). Beyond more "popular" variables such as $\mathrm{VO}_{2} \max$, the maximal oxygen consumption during exercise, other variables such as the oxygen pulse $\left(\mathrm{O}_{2}\right.$ pulse) and its derived curve have emerged as potential indicators of cardiovascular disease.

The $\mathrm{O}_{2}$ pulse is the ratio of $\mathrm{VO}_{2}$ to heart rate and reflects the amount of $\mathrm{O}_{2}$ extracted per heart beat, providing an estimate of left ventricular stroke volume changes during exercise, if anemia is not present. The normal physiological response to progressive exercise is a continuously increasing $\mathrm{O}_{2}$ pulse, a linear increase in $\mathrm{VO}_{2}$ versus work rate, and a linear increase in heart rate versus $\dot{\mathrm{VO}}_{2}$ until peak values are reached (Whipp et al. 1996, Klainman et al. 2002, Lim et al. 2005). The development of myocardial ischemia during exercise can lead to loss of augmentation of stroke volume, which appears as a flattening of the $\mathrm{O}_{2}$ pulse curve. A flat or downward $\mathrm{O}_{2}$ curve has been suggested to indicate the presence of exercise-induced myocardial ischemia assessed by myocardial perfusion imaging (Belardinelli et 
al. 2003, Muñoz et al. 2007). We have recently shown, however, an association between myocardial fibrosis and $\mathrm{O}_{2}$ pulse abnormality (De Lorenzo et al. 2017). It remains to be demonstrated, though, the value of the $\mathrm{O}_{2}$ pulse curve pattern for the diagnosis of the presence and extent of CAD using invasive coronary angiography as the gold standard. Thus, the aim of this study was to evaluate the diagnostic properties of the $\mathrm{O}_{2}$ pulse curve in patients with known coronary anatomy who underwent CPET with radiotracer injection for myocardial perfusion scintigraphy, a protocol that also allows for the evaluation of myocardial ischemia and fibrosis in addition to other physiological data obtained at CPET.

\section{Methods}

Patients $\geq 18$ years, with known coronary artery anatomy (defined at coronary angiography performed within 3 months of recruitment) were considered eligible for the study. Exclusion criteria were left ventricular dysfunction $(<45 \%$ left ventricular ejection fraction on a transthoracic echocardiogram), the presence of other cardiac diseases (e.g. primary valve disease or cardiomyopathies), acute coronary syndrome $<3$ months, uncontrolled hypertension, uncontrolled arrhythmias, third-degree left bundle branch block, pacemaker rhythm, stable angina classes III or IV, anemia (serum hemoglobin $<12 \mathrm{~g} / \mathrm{dl}$ ), $\geq 50 \%$ left main coronary artery disease, chronic pulmonary disease or inability to exercise.

Significant CAD was considered as any $\geq 50 \%$ stenosis in a major epicardial coronary artery. Multivessel CAD was considered as the presence of significant CAD in $\geq 2$ coronary arteries.

The research was approved by the institutional ethics committee and was performed in compliance with the 1975 Declaration of Helsinki. Informed consent was obtained from each subject.

\section{Study protocol}

All patients underwent CPET with radiotracer injection during exercise and myocardial perfusion scintigraphy on the same day. Antianginal medications were stopped before the CPET (nitrates for $24 \mathrm{~h}$, calcium antagonists and beta-blockers for 2 days). A symptomlimited CPET was performed on a treadmill (Ergo PC Elite, Micromed, Brasilia, Brazil). Heart rate and blood pressure were measured every minute during exercise and recovery. A 12-lead ECG was continuously evaluated and recorded every $3 \mathrm{~min}$. After calibration of the volumes and gas exchange analyzers, patients breathed through a mask connected to a two-way respiratory valve. Expired gases and volumes were analyzed $\left(\mathrm{VO}_{2000}\right.$, MedGraphics, MN, EUA). All individuals underwent CPET with a ramp protocol (Balady et al. 2010). $\mathrm{O}_{2}$ pulse and $\mathrm{O}_{2}$ pulse curves were automatically obtained. The $\mathrm{O}_{2}$ pulse curves were interpreted by two experienced examiners who were blinded to clinical and MPS data and were classified as: A - normal; B - probably normal (normal slope with lower values); $\mathrm{C}$ - probably abnormal (flat and low); or $\mathrm{D}$ - definitely abnormal (descending slope) (Klainman et al. 2002). The agreement between observers, evaluated with kappa statistic, was 0.65 (CI $95 \% 0.39-0.66$ ). The final interpretation of the curve pattern was defined by consensus. Sensitivity, specificity, positive and negative predictive values of the pattern of the $\mathrm{PuO}_{2}$ curves were assessed using the presence of angiographically defined $\mathrm{CAD}$ as the gold standard. For these analyses, normal or probably normal curves $(\mathrm{A} / \mathrm{B})$ were studied together. Similarly, probably abnormal or definitely abnormal curves $(\mathrm{C} / \mathrm{D})$ were grouped.

At near-maximal exercise, ${ }^{99 \mathrm{~m}} \mathrm{Tc}$-sestamibi (20-25 mCi) was injected intravenously, and exercise was continued at maximal workload for at least $1 \mathrm{~min}$. Exercise was terminated if there was increasing angina, a fall in blood pressure $>20 \mathrm{~mm} \mathrm{Hg}$, limiting dyspnea or fatigue or sustained arrhythmias. Significant ST-segment depression was defined as that $\geq 1.5 \mathrm{~mm}$, horizontal or downsloping, $80 \mathrm{~ms}$ after the J-point. Up to $60 \mathrm{~min}$ after tracer injection, myocardial perfusion scintigraphy was performed in an Infinia Hawkeye 4 camera (General Electric Healthcare, WI, EUA). Resting images were obtained on a separate day after injection of ${ }^{99 \mathrm{~m}}$ Tc-sestamibi (20-25 mCi). Perfusion scores were calculated and expressed the extent and severity of total, resting and ischemic perfusion defects (summed stress, rest and difference scores - SSS, SRS and SDS respectively) (Berman et al. 1995). Ischemia was considered present when the SDS was $>1$. Left ventricular ejection fraction (LVEF) was automatically obtained with QGS software (Cedars-Sinai Medical Center, Los Angeles, California, USA). Images were blindly interpreted by 2 experienced observers and the final results were defined by consensus. 


\section{Statistical analysis}

Categorical variables, presented as frequencies with percentages, were compared using Fisher's exact test or the chi-square test. Continuous variables, presented as mean \pm SD or median and interquartile range, were compared using Student's $t$-test or Mann-Whitney's U test, whenever appropriate. A logistic regression analysis was used to identify, among clinical, CPET and scintigraphic variables, those with an independent association with angiographically defined CAD. A value of $\mathrm{p}<0.05$ was considered statistically significant in all analyses. Calculations were performed using R software, version 3.2.2.

\section{Results}

Patient characteristics, CPET and scintigraphic data are shown in Table 1. Fourteen patients (35.0\%) had normal coronary arteries, $11(27.0 \%)$ had single-vessel CAD and $15(38.0 \%)$ had multivessel CAD. Table 2 depicts the comparison between patients with or without CAD. The former were older, had higher rates of diabetes, smoking, hypercholesterolemia and stable angina, and more often used antiplatelet drugs, angiotensin-converting enzyme inhibitors and nitrates. Exercise duration was shorter, as well as peak heart rate, in patients with CAD. They also had a higher prevalence of ischemia, higher SSS and SDS.

Table 1. Demographic, clinical, CPET and scintigraphic data.

$\mathrm{N}(\%)$ or mean $\pm \mathrm{SD}$

\begin{tabular}{lc}
\hline Age (years) & $57.0 \pm 9.6$ \\
Male & $24(60.0)$ \\
Body mass index $\left(\mathrm{kg} / \mathrm{m}^{2}\right)$ & $27.5 \pm 4.5$ \\
Hypertension & $34(85.0)$ \\
Diabetes & $9(22.5)$ \\
Stable angina & $25(62.5)$ \\
Prior myocardial infarction & $19(47.5)$ \\
Medications & \\
Beta-blockers & $27(67.5)$ \\
Antiplatelets & $33(82.5)$ \\
Statins & $28(70.0)$ \\
Angiotensin-converting inhibitors & $39(97.5)$ \\
Calcium channel antagonists & $13(32.5)$ \\
Nitrates & $18(45.0)$ \\
Coronary angiography & \\
Normal coronary arteries & $14(35.0)$ \\
Single-vessel & $11(27.0)$ \\
Multivessel & $15(38.0)$ \\
Hemoglobin (g/dl) & $13.8 \pm 1.3$ \\
\hline
\end{tabular}

CPET, cardiopulmonary exercise test.

Figure 1 shows examples of the four possible curve patterns. The evaluation of the diagnostic performance of the $\mathrm{O}_{2}$ pulse curves showed that there were 16 patients (40.0\% of the total number of patients) with $\mathrm{A} / \mathrm{B}$ curves and angiographically defined CAD (false-negatives). Eleven patients $(27.5 \%$ of the total) had $\mathrm{A} / \mathrm{B}$ curves and no CAD (true-negatives). Probably or definitely abnormal curves (C/D) were found in
10 patients with $\mathrm{CAD}(25.0 \%$ of the whole population were true-positives). Finally, $\mathrm{C} / \mathrm{D}$ curves occurred in 3 patients without CAD $(7.5 \%$ of false-positives). Interestingly, there was no association between ischemic ST-segment changes and the $\mathrm{O}_{2}$ pulse curve patterns ( $43.3 \%$ in $\mathrm{A} / \mathrm{B}$ curves versus $30 \%$ in $\mathrm{C} / \mathrm{D}$ curves, $\mathrm{p}=1$ ).

Sensitivity, specificity, positive and negative predictive values of the $\mathrm{O}_{2}$ pulse curve pattern 
(considering the $\mathrm{C} / \mathrm{D}$ patterns as abnormal $\mathrm{O}_{2}$ pulse and using the presence of angiographically defined CAD as the gold standard) were, respectively, 38.5\%, 78.6\%, $76.9 \%$, and $40.7 \%$. Additionally, the sensitivity, specificity, positive and negative predictive values of the $\mathrm{C} / \mathrm{D} \mathrm{O}_{2}$ pulse curve pattern for the diagnosis of multivessel CAD were, respectively, $29.4 \%, 65.2 \%$, $38.5 \%$, and $55.6 \%$.

Table 2. Comparisons between patients with or without coronary artery disease (CAD).

\begin{tabular}{|c|c|c|}
\hline Demographic and clinical data & With CAD $(n=26)$ & Without CAD $(n=14)$ \\
\hline Age (years) & $59.5 \pm 10.0$ & $53.0 \pm 6.6^{*}$ \\
\hline Male & $18(69.2 \%)$ & $6(42.8 \%)$ \\
\hline Body mass index $\left(\mathrm{kg} / \mathrm{m}^{2}\right)$ & $27.6 \pm 3.7$ & $27.3 \pm 5.8$ \\
\hline Hypertension & $22(84.6 \%)$ & $12(85.7 \%)$ \\
\hline Diabetes & $9(34.6 \%)$ & $0^{*}$ \\
\hline Hypercholesterolemia & $22(84.6 \%)$ & $7(50.0 \%)^{*}$ \\
\hline Smoking & $23(88.5 \%)$ & $9(64.2 \%)^{*}$ \\
\hline Stable angina & $23(88.5 \%)$ & $2(14.3 \%)^{*}$ \\
\hline Beta-blocker & $20(76.9 \%)$ & $7(50.0 \%)$ \\
\hline Antiplatelet agents & $24(92.3 \%)$ & $9(64.2 \%)^{*}$ \\
\hline Statins & $20(76.9 \%)$ & $8(57.1 \%)$ \\
\hline Angiotensin-converting enzyme inhibitors & $11(42.3 \%)$ & $1(7.1 \%)^{*}$ \\
\hline Calcium channel blockers & $9(34.6 \%)$ & $4(28.6 \%)$ \\
\hline Nitrates & $15(57.6 \%)$ & $3(21.4 \%)^{*}$ \\
\hline \multicolumn{3}{|l|}{ CPET } \\
\hline Exercise duration (min) & $7.8 \pm 3.2$ & $9.7 \pm 1.5^{*}$ \\
\hline ST depression & $12(46.1 \%)$ & $4(28.5 \%)$ \\
\hline Peak heart rate (bpm) & $137.0 \pm 16.6$ & $151 \pm 20.4^{*}$ \\
\hline$\%$ maximal predicted heart rate & $85.7 \pm 11.9$ & $90.6 \pm 11.6$ \\
\hline Heart rate recovery (bpm) & $18.5 \pm 10.0$ & $19.6 \pm 7.9$ \\
\hline Peak systolic blood pressure ( $\mathrm{mm} \mathrm{Hg}$ ) & $176.0 \pm 28.0$ & $186.0 \pm 28.9$ \\
\hline \multicolumn{3}{|l|}{$\mathrm{PuO}_{2}$ curve pattern } \\
\hline$A$ & $6(23.1 \%)$ & $3(21.4 \%)$ \\
\hline$B$ & $13(50.0 \%)$ & $8(57.1 \%)$ \\
\hline$C$ & $6(23.1 \%)$ & $3(21.4 \%)$ \\
\hline$D$ & $1(3.8 \%)$ & 0 \\
\hline $\mathrm{VO}_{2} \max$ & $18.4 \pm 5.9$ & $21.8 \pm 4.8$ \\
\hline \multicolumn{3}{|l|}{ Myocardial perfusion scintigraphy } \\
\hline$S S S$ & $13.4 \pm 9.3$ & $4.6 \pm 4.9^{*}$ \\
\hline$S R S$ & $6.7 \pm 8.6$ & $3.0 \pm 4.2$ \\
\hline$S D S$ & $6.6 \pm 6.3$ & $1.6 \pm 2.3 *$ \\
\hline Ischemia & $23(88.5 \%)$ & $4(28.5 \%)^{*}$ \\
\hline Post-stress left ventricular ejection fraction (\%) & $52.5 \pm 13.8$ & $55.0 \pm 10.0$ \\
\hline
\end{tabular}

$* \mathrm{p}<0.05$. CAD, coronary artery disease; CPET, cardiopulmonary exercise test; $\mathrm{PuO}_{2}$, oxygen pulse; SSS, summed stress score; SRS, summed rest score; SDS, summed difference score; $\mathrm{VO}_{2}$ max, maximal oxygen consumption.

Of note, the concordance rate between the abnormal $\mathrm{O}_{2}$ pulse curve pattern and myocardial perfusion scintigraphy (considering only ischemic scintigraphic studies) was $38.1 \%$. Abnormal curves without scintigraphic evidence of ischemia occurred in 5 patients, among whom 3 had large areas of fibrosis 
and documented CAD, and 2 had normal perfusion and no CAD. Normal curves with scintigraphic ischemia were found in 20 patients, 15 of them ( $75 \%)$ with CAD. Sensitivity, specificity, positive and negative predictive values of the abnormal $\mathrm{O}_{2}$ pulse curve pattern (C/D) using the presence of myocardial ischemia defined by scintigraphy were, respectively, $61.5 \%, 31.0 \%$, $28.6 \%$ and $64.3 \%$. Figure 2 shows an example of a patient with 3-vessel $\mathrm{CAD}$, abnormal $\mathrm{O}_{2}$ pulse curve and myocardial scintigraphy without ischemia, but with a large nonreversible perfusion defect, indicating myocardial fibrosis.

In the logistic regression analysis, the final adjusted model showed that age and the SSS were significantly associated with the presence of $\mathrm{CAD}$, such that for each year of increasing age and for each unit of the SSS, the chance of having CAD increased $18 \%$ and $27 \%$, respectively (Table 3 ). Abnormal $\mathrm{O}_{2}$ pulse curve patterns (B or $\mathrm{C}$ or both combined) were not independently associated with $\mathrm{CAD}$ at coronary angiography.
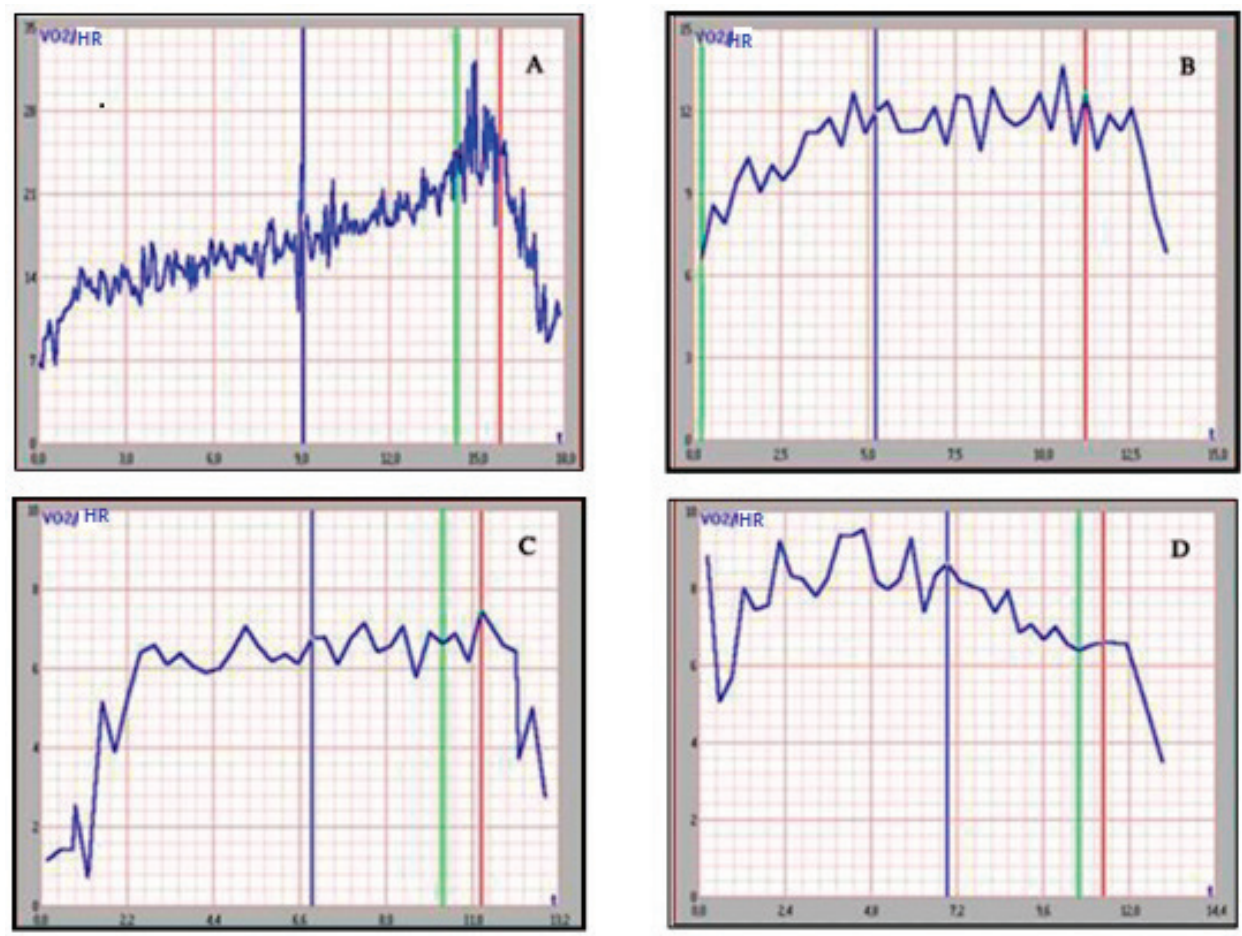

Fig. 1. Examples of $\mathrm{O}_{2}$ pulse curves. (A) normal curve. (B) probably normal curve. (C) probably abnormal curve. (D) definitely abnormal curve.
A

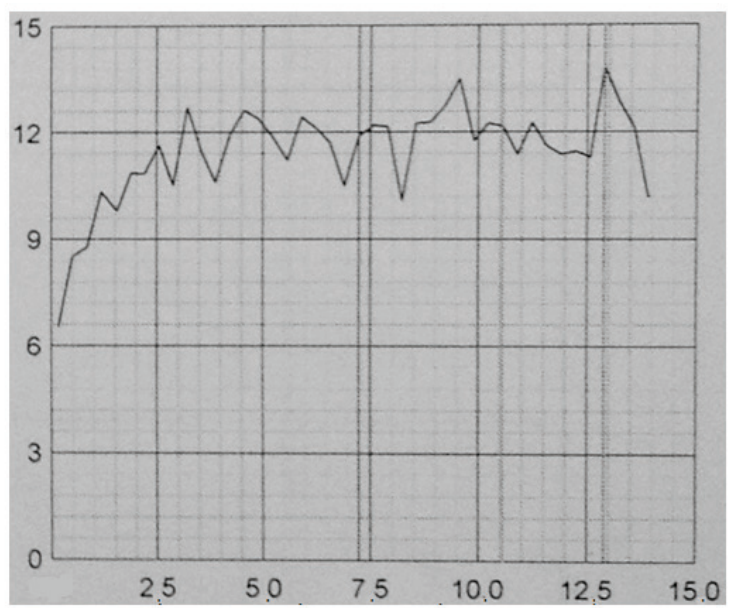

B

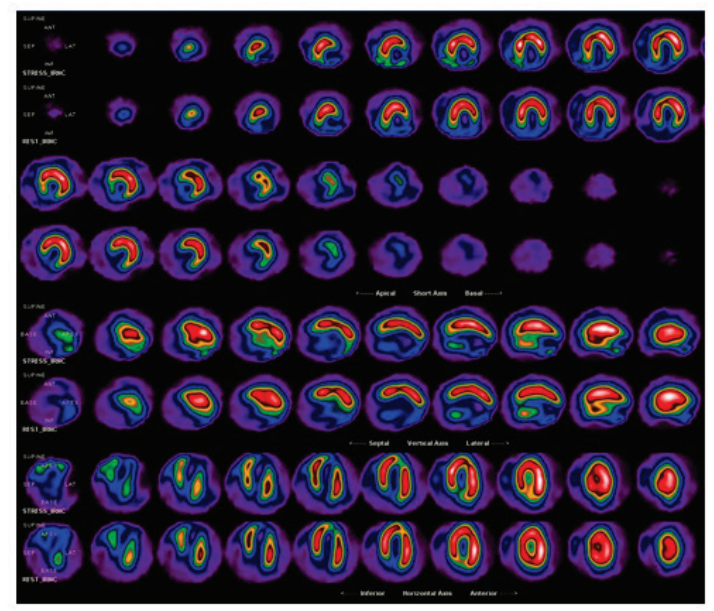

Fig. 2. A 60-year-old woman with stable angina, prior myocardial infarction and coronary angiography showing $70 \%$ left anterior descending, $70 \%$ left circumflex and $100 \%$ right coronary artery obstructions. (A) flat $\mathrm{O}_{2}$ pulse curve, with probably abnormal (C) pattern. X-axis: time (min). Y-axis: oxygen consumption in $\mathrm{ml} /$ heartbeat $\left(\mathrm{VO}_{2} /\right.$ beat). (B) stress/rest myocardial perfusion scintigraphy showing a large, nonreversible apical and inferior wall defect. 


\section{Discussion}

Cardiopulmonary exercise testing (CPET), with measures such as oxygen uptake and oxygen pulse, provides objective and reproducible indices that may be used for diagnostic and prognostic evaluation of cardiovascular disease. Indeed, CPET is an important non-invasive tool, while usually not employed to its full clinical potential. Reasons for that may include limited availability of the equipment or of trained personnel, but also the paucity of information upon its diagnostic usefulness, especially regarding CAD. This study therefore evaluated the diagnostic application of CPET for CAD assessment, using the pattern of the $\mathrm{O}_{2}$ pulse curve as an indicator of exercise-induced ischemia, compared to the detection of ischemia by myocardial perfusion scintigraphy and to the objective evidence of $\mathrm{CAD}$ at coronary angiography.

In this study, all participants had documented coronary artery anatomy, defined by invasive coronary angiography. This is a major strength, as most published data on the value of the $\mathrm{O}_{2}$ pulse curve do not have coronary artery anatomy data for comparison (Klainman et al. 1996, Belardinelli et al. 2003). Belardinelli et al. (2003) have evaluated the diagnostic accuracy of the $\mathrm{O}_{2}$ pulse in patients with known CAD, but the control group was comprised of supposedly healthy individuals, without a confirmation of normal coronary arteries. In our series, patients had a distribution of CAD severity of approximately $1 / 3$ of normal coronary arteries, $1 / 3$ of single-vessel CAD and $1 / 3$ of multivessel CAD, an optimal model for the assessment of the diagnostic properties of a noninvasive method. It may be intriguing that a third of the patients who underwent coronary angiography had normal coronaries, but that might be explained as the exam had been indicated by assisting physicians, who might have ordered the test due to persistent anginal symptoms, ischemic exercise tests (with ST- segment criteria for ischemia), equivocal or even abnormal myocardial perfusion scintigraphy results.

The diagnostic performance of the $\mathrm{O}_{2}$ pulse curves using $\mathrm{CAD}$ detected at coronary angiography as the gold standard showed that sensitivity was very low, as well as the negative predictive value, while specificity and the positive predictive value were good or reasonable. This indicates a problem of the $\mathrm{O}_{2}$ pulse curve patterns both to detect disease when present, as well as to exclude it when absent. Interestingly, when considering the presence of multivessel CAD, what theoretically would increase the ischemic burden and facilitate ischemia detection by the $\mathrm{PuO}_{2}$ curve patterns, the sensitivity was indeed reduced, while the other remained unchanged or were also reduced.

The comparison of a functional test (CPET, with its variables such as the $\mathrm{O}_{2}$ pulse) with an anatomic test (coronary angiography) may be viewed as inadequate, even with coronary anatomy being, for decades, the gold standard for all noninvasive diagnostic tests. So we compared the $\mathrm{O}_{2}$ pulse curve pattern to the results of myocardial perfusion scintigraphy, both functional tests. The concordance rate between the $\mathrm{O}_{2}$ pulse curve pattern and myocardial perfusion at peak exercise was low slightly over $30 \%$. This was a peculiar finding, as the $\mathrm{PuO}_{2}$ abnormality was expected to correlate with myocardial ischemia, according to previous data (Belardinelli et al. 2003, Muñoz et al. 2007). It should be noted, though, that for this study, only ischemic scintigraphic studies were used to define a "positive" scintigraphy. Discordances considered as the absence of scintigraphic ischemia in patients with abnormal $\mathrm{O}_{2}$ pulse curves (which were found in 5 patients) were in $40 \%$ of the cases due to truly "false-positive" curves (when both scintigraphy and coronary angiography were normal), but in $60 \%$ of the patients might be attributed to the definition of "abnormal" scintigraphy used in this study the presence of ischemia. In fact, these patients had large areas of fibrosis without ischemia, and $\mathrm{O}_{2}$ pulse curves were abnormal. So, as further indicated by other data from our study, the underlying mechanism of the $\mathrm{O}_{2}$ pulse abnormality is probably chronic left ventricular myocardial dysfunction-even in the absence of a reduced left ventricular ejection fraction.

The fact that the occurrence of exercise-induced myocardial ischemia does not seem to be intrinsically associated with the $\mathrm{O}_{2}$ pulse abnormality is also suggested by the 20 patients who had "negative" (normal or probably normal) curves with scintigraphic ischemia, $75 \%$ of whom had angiographically documented CAD. It is worth noting that most of these patients (12 out of 15) had 1 or 2-vessel CAD, what might suggest a reduced ability of the $\mathrm{O}_{2}$ pulse curve to identify patients with small to moderate amounts of ischemia. This is in line with the results of Munoz et al. (2007), who only found abnormal $\mathrm{O}_{2}$ pulse curves in patients with extensive ischemia. The multivariable analysis corroborated the initial findings, showing that the total amount of 
perfusion defect (and not the presence or extent of ischemia) and the abnormal $\mathrm{O}_{2}$ pulse curve patterns ( $\mathrm{B}$ or $\mathrm{C}$ or both combined) were not independently associated with angiographically confirmed CAD.

\section{Limitations}

This study is limited by the small sample size. Larger patient number would enable further inferences, such as the evaluation of the effect of different severities of coronary artery obstruction, of different coronary anatomies (e.g. left anterior descending versus right coronary artery), or of lesion location (proximal versus distal) on the pattern of the $\mathrm{O}_{2}$ pulse curve. With the current patient sample, only the number of coronary arteries with significant lesions could be used for evaluation.

\section{Conclusions}

The $\mathrm{O}_{2}$ pulse curve pattern has low sensitivity and negative predictive value for the diagnosis of obstructive CAD. Abnormal $\mathrm{O}_{2}$ pulse curve pattern was not associated with myocardial ischemia defined by scintigraphy; the mechanism underlying the $\mathrm{O}_{2}$ pulse abnormality most likely is myocardial dysfunction, even if global left ventricular function is not compromised, as the extent of global perfusion defect was significantly associated with abnormal $\mathrm{O}_{2}$ pulse curve patterns.

\section{Conflict of Interest}

There is no conflict of interest.

\section{Acknowledgements}

We thank dr. Pablo Marino for the help in discussion of CPET tracings.

\section{References}

BALADY GJ, ARENA R, SIETSEMA K, MYERS J, COKE L, FLETCHER GF, FORMAN D, FRANKLIN B, GUAZZI M, GULATI M, KETEYIAN SJ, LAVIE CJ, MACKO R, MANCINI D, MILANI RV; AMERICAN HEART ASSOCIATION EXERCISE, CARDIAC REHABILITATION, AND PREVENTION COMMITTEE OF THE COUNCIL ON CLINICAL CARDIOLOGY; COUNCIL ON EPIDEMIOLOGY AND PREVENTION; COUNCIL ON PERIPHERAL VASCULAR DISEASE; INTERDISCIPLINARY COUNCIL ON QUALITY OF CARE AND OUTCOMES RESEARCH: Clinician's guide to cardiopulmonary exercise testing in adults: a scientific statement from the American Heart Association. Circulation 122: 191-225, 2010.

BELARDINELLI R, LACALAPRICE F, CARLE F, MINNUCCI A, CIANCI G, PERNA G, D'EUSANIO G: Exerciseinduced myocardial ischaemia detected by cardiopulmonary exercise testing. Eur Heart J 24: 1304-1313, 2003.

BERMAN DS, HACHAMOVITCH R, KIAT H, COHEN I, CABICO JA, WANG FP, FRIEDMAN JD, GERMANO G, VAN TRAIN K, DIAMOND GA: Incremental value of prognostic testing in patients with known or suspected ischemic heart disease: a basis for optimal utilization of exercise technetium-99m sestamibi myocardial perfusion single-photon emission computed tomography. J Am Coll Cardiol 26: 639-647, 1995.

DE LORENZO A, DA SILVA CL, SOUZA FCC, SERRA S, MARINO P, LIMA RSL: Clinical, scintigraphic, and angiographic predictors of oxygen pulse abnormality in patients undergoing cardiopulmonary exercise testing. Clin Cardiol 40: 914-918, 2017.

GUAZZI M, ADAMS V, CONRAADS V, HALLE M, MEZZANI A, VANHEES L, ARENA R, FLETCHER GF, FORMAN DE, KITZMAN DW, LAVIE CJ, MYERS J, EACPR, AHA: EACPR/AHA Joint Scientific Statement. Clinical recommendations for cardiopulmonary exercise testing data assessment in specific patient populations. Eur Heart J 33: 2917-2927, 2012.

KLAINMAN E, KUSNIEC J, STERN J, FINK G, FARBSTEIN H: Contribution of cardiopulmonary indices in the assessment of patients with silent and symptomatic ischemia during exercise testing. Int J Cardiol 53: 257-263, 1996.

KLAINMAN E, GERSHON F, LEBZELTER J, KREULBAUMM T, KRAMER MR: The relationship between left ventricular function assessed by multigated radionuclide test and cardiopulmonary exercise test in patients with ischemic heart disease. Chest 121: 841-845, 2002. 
LIM JG, MCAVENEY TJ, FLEG JL, SHAPIRO EP, TURNER KL, BACHER AC, OUYANG P, STEWART KJ: Oxygen pulse during exercise is related to resting systolic and diastolic left ventricular function in older persons with mild hypertension. Am Heart $J$ 150: 941-946, 2005.

MUÑOZ EC, HOLLANDA R, VARGAS JP, SILVEIRA CW, LEMOS AL, HOLLANDA RM, RIBEIRO JP: Flattening of oxygen pulse during exercise may detect extensive myocardial ischemia. Med Sci Sports Exerc 39: 1221-1226, 2007.

MYERS J, GULLESTAD L: The role of exercise testing and gas-exchange measurement in the prognostic assessment of patients with heart failure. Cur Opin Cardiol 13: 145-155, 1998.

WHIPP BJHM, HIGGENBOTHAM MB, COBB FC: Estimating exercise stroke volume form asymptotic oxygen pulse. J Appl Physiol 81: 2674-2679, 1996. 